\section{Genetic association of non-MHC region with ankylosing spondylitis in a Chinese population}

Ankylosing spondylitis (AS) is a chronic inflammatory disease mainly affecting the sacroiliac joints and spine. ${ }^{1}$ In order to examine overall genetic susceptibility of AS, several genome-wide association studies (GWASs) were performed in Caucasian populations, and a number of genetic polymorphisms in non-major histocompatibility complex (MHC) regions were found, such as ERAP1, IL23R as well as many others. ${ }^{2-6}$ However, only a small portion of the single nucleotide polymorphisms (SNPs) were validated in East Asian (EA) populations. ${ }^{2}$ In recent years, multiple studies indicated significant genetic differences between different European and EA populations. ${ }^{27}$ To resolve this further, we have examined all reported AS-associated SNPs in non-MHC regions in Chinese patients with AS. A total of 1289 patients with AS and 1536 controls were included in this analysis, which have not been included in prior analyses. ${ }^{27}$ The sociodemographic and clinical characteristics of the cohort are presented in online supplementary table S1.

In this study, the candidate SNPs were mainly selected from six GWAS studies published from 2007 to $2016 .^{2-68}$ Overall, 69 SNPs in non-MHC regions were included, 32 of which had not been validated in EA population before. The results of six loci (rs6759298, rs2297518, rs75301646, rs12615545, rs5837881 and rs27044) were consistent with prior reports in the Caucasian populations (table 1). Among them, the SNP rs2297518 in the NOS2 gene (OR/p_value (false discovery rate $(\mathrm{FDR}))=1.328 / 8.6 \mathrm{E}-03)$ and rs5837881 in an intergenic region $\left(\mathrm{OR} / \mathrm{p}_{-}\right.$value $\left.(\mathrm{FDR})=0.80 / 0.04\right)$ were not validated previously in EA populations, whereas four other SNPs were consistent with previous reports in Asian cohorts. ${ }^{27}$ Nine loci that had been previously associated with AS in relatively small cohorts of Chinese population were not validated in the present results (online supplementary table S2). Twenty-four loci that previously showed an association with AS but with $\mathrm{p}$ value not at genome-wide significance $\left(>10^{-8}\right)$ in both Caucasian and EA populations were not validated in our results (online supplementary table S3). Thirty-one loci previously reported implicated only in Caucasians did not show an association with AS in this study (online supplementary table S4).

In this study, all six SNPs showed significant differentiation between AS and controls in both Caucasians and our samples. Among them, rs6759298 located in a 'gene desert' at chromosome $2 \mathrm{p} 15$ showed highest significance in both Caucasian and Chinese data $(\mathrm{OR} / \mathrm{p}$ value $=1.31 / 3.60 \mathrm{E}-41,1.22 / 3.81 \mathrm{E}-04$, respectively). The Genotype-Tissue Expression dataset showed that rs6759298 has expression quantitative trait loci (eQTL) with B3GNT2 (online supplementary figure 1A). In addition, the database of Mouse Genome Informatics (MGI) showed that mice with B3gnt2-knocked-out showed increased levels of inflammatory cytokines such as interleukin (IL)-6, IL-1 $\beta$ and tumour necrosis factor-alpha). An association with another SNP (rs2297518) located in NOS2, which has never been reported in Chinese data of patients with AS, was found. It is a mutation that causes deleterious alterations in the coding region of NOS2. Rs75301646 is an intron variant on SULT1A2, which has eQTL with SULT1A1 expression (online supplementary figure 1B). MGI showed Sult1c1-knockout- mice have abnormal immune responses and increased sacral vertebrae number. Rs12615545 is near UBE2E3 and has eQTL with UBE2E3 (ubiquitin enzyme)

Table 1 Genetic associations with AS and controls in the Chinese population

\begin{tabular}{|c|c|c|c|c|c|c|c|c|c|c|}
\hline \multirow[b]{2}{*}{ Gene/region } & \multirow[b]{2}{*}{ SNP } & \multirow[b]{2}{*}{ Allele } & \multicolumn{2}{|c|}{ Western } & \multicolumn{2}{|c|}{ Asian } & \multicolumn{4}{|l|}{ This study } \\
\hline & & & OR & $P$ values & OR & $P$ values & MAF & OR & $P$ values & P_adj \\
\hline $2 p 15^{2}$ & rs6759298 & G & 1.31 & $3.60 \mathrm{E}-41$ & 1.28 & $1.60 \mathrm{E}-06$ & $0.4418 / 0.3917$ & 1.22 & $3.81 \mathrm{E}-04$ & $8.60 \mathrm{E}-03$ \\
\hline NOS2 ${ }^{2}$ & rs2297518 & A & 1.13 & $6.30 \mathrm{E}-07$ & NA & NA & $0.176 / 0.1387$ & 1.33 & $1.83 \mathrm{E}-04$ & $8.60 \mathrm{E}-03$ \\
\hline SULTIA1 ${ }^{2}$ & rs75301646 & A & 1.11 & $1.40 \mathrm{E}-07$ & 1.16 & 0.012 & $0.292 / 0.2472$ & 1.26 & $2.55 \mathrm{E}-04$ & $8.60 \mathrm{E}-03$ \\
\hline UBE2E3 $^{2}$ & rs12615545 & T & 0.90 & $2.30 \mathrm{E}-07$ & 0.83 & $8.50 \mathrm{E}-04$ & $0.2959 / 0.3379$ & 0.82 & $6.66 \mathrm{E}-04$ & 0.01 \\
\hline Chr2 Indel ${ }^{6}$ & rs5837881 & $T$ & 0.88 & $1.26 \mathrm{E}-13$ & NA & NA & $0.149 / 0.18$ & 0.80 & $3.14 \mathrm{E}-03$ & 0.04 \\
\hline ERAP1 $^{310}$ & rs27044 & C & 0.71 & $1.00 \mathrm{E}-06$ & 1.30 & $9.37 \mathrm{E}-07$ & $0.4694 / 0.5046$ & 0.86 & 4.70E-03 & 0.05 \\
\hline
\end{tabular}

$\mathrm{AS}$, ankylosing spondylitis; MAF, minor allele frequency. 
in oesophageal mucosa, suggesting it might be related to inflammation status (online supplementary figure S1C).

Other loci were not validated in our samples such as IL12B, ANTXR2 and FCGR $2 A .{ }^{9}$ We postulated that some different SNPs located in the same genes or genes in the same pathway can substitute for those loci in the Chinese population as has been observed with $I L 23 R .^{2}$ Therefore, it is essential to find associated SNPs in different cohorts by sequencing or different chip analyses to extend our knowledge to the pathogenesis of AS.

In conclusion, we genotyped 69 previously reported non-MHC AS-associated SNPs in a different Chinese cohort and found that six loci showed significant differences between patients with AS and controls in both Caucasian and EA populations. Usually, several SNPs may have similar effect to the same gene. Therefore, in the future, we can perform functional study of genes controlled by several SNPs in the mouse.

\section{Jing Liu, ${ }^{1,2}$ Weilin $\mathrm{Pu}^{1,2}$ Yuan $\mathrm{Li}^{1,2}$ Yanyun $\mathrm{Ma}^{2,3} \mathrm{Qi}$ Zhu, ${ }^{4}$ Wei Wan, ${ }^{5}$ Chengde Yang, ${ }^{6}$ Xiaofeng Wang, ${ }^{1,2}$ Xingdong Chen, ${ }^{1,7}$ Xiaodong Zhou, ${ }^{8}$ John D Reveille, ${ }^{8}$ Li Jin, ${ }^{1,2}$ Hejian Zou, ${ }^{9,10}$ Jiucun Wang ${ }^{1,11}$}

${ }^{1}$ State Key Laboratory of Genetic Engineering, Collaborative Innovation Center for Genetics and Development, School of Life Sciences, Fudan University, Shanghai, China

${ }^{2}$ Human Phenome Institute, Fudan University, Shanghai, China

${ }^{3}$ Ministry of Education Key Laboratory of Contemporary Anthropology, Department of Anthropology and Human Genetics, School of Life Sciences, Fudan University, Shanghai, China

${ }^{4}$ Institute of Arthritis Research, Shanghai Academy of Chinese Medical Sciences, Guanghua Integrative Medicine Hospital, Shanghai, China

${ }^{5}$ Division of Rheumatology and Immunology, Changhai Hospital, Shanghai, China

${ }^{6}$ Division of Rheumatology, Ruijin Hosptial, Shanghai Jiaotong University Schools of Medicine, Shanghai, China

${ }^{7}$ Fudan-Taizhou Institute of Health Sciences, Taizhou, China

${ }^{8}$ Division of Rheumatology and Clinical Immunogenetics, The University of TexasMcGovern Medical School, Houston, TX, United States

${ }^{9}$ Division of Rheumatology, Huashan Hospital, Fudan University, Shanghai, China ${ }^{10}$ Institute of Rheumatology, Immunology and Allergy, Fudan University, Shanghai, China

${ }^{11}$ Division of Dermatology, Huashan Hospital, Fudan University, Shanghai, China

Correspondence to Professor Jiucun Wang, State Key Laboratory of Genetic Engineering, School of Life Sciences, Fudan University, Division of Dermatology, Huashan Hospital, Shanghai 200438, China; jcwang@fudan.edu.cn and Hejian Zou, Division of Rheumatology, Huashan Hospital, Fudan University, Shanghai, China; hjzou@fudan.edu.cn

\section{Handling editor Josef S Smolen}

Contributors JW and $\mathrm{HZ}$ designed the project and wrote the manuscript. JL and WP collected data, performed genotyping and analysis and wrote the manuscript. YL and YM managed all samples. QZ, WW and CY provided the ankylosing spondylitis samples. XW and XC provided the control samples. XZ, JDR and LJ revised the manuscript and provided valuable suggestions.

Funding The study was supported by research grants from the National Basic Research Program (2014CB541801), National Natural Science Foundation of China (31521003), Shanghai Municipal Science and Technology Major Project (2017SHZDZX01), International S\&T Cooperation Program of China (2013DFA30870), 111 Project (B13016) and US NIH NIAID U01 (1U01AI090909) and China Medical Foundation. Computational support was provided by theHighEnd Computing Center located at Fudan University.

Competing interests None declared

Patient consent for publication Obtained.

Ethics approval Fudan University.

Provenance and peer review Not commissioned; externally peer reviewed.
Open access This is an open access article distributed in accordance with the Creative Commons Attribution Non Commercial (CC BY-NC 4.0) license, which permits others to distribute, remix, adapt, build upon this work non-commercially, and license their derivative works on different terms, provided the original work is properly cited, appropriate credit is given, any changes made indicated, and the use is non-commercial. See: http://creativecommons.org/licenses/by-nc/4.0/.

(C) Author(s) (or their employer(s)) 2019. Re-use permitted under CC BY-NC. No commercial re-use. See rights and permissions. Published by BMJ.

- Additional material is published online only. To view please visit the journal online (http://dx.doi.org/10.1136/annrheumdis-2018-214625).

$J \mathrm{~L}$ and WP contributed equally.

$$
\text { Check for updates }
$$

To cite Liu J, Pu W, Li Y, et al. Ann Rheum Dis 2019;78:852-853.

Received 21 October 2018

Revised 8 November 2018

Accepted 12 November 2018

Published Online First 14 December 2018

Ann Rheum Dis 2019:78:852-853. doi:10.1136/annrheumdis-2018-214625

\section{REFERENCES}

1 Brown MA, Kennedy LG, MacGregor AJ, et al. Susceptibility to ankylosing spondylitis in twins: the role of genes, HLA, and the environment. Arthritis Rheum 1997;40:1823-8.

2 Wellcome Trust Case Control Consortium, Australo-Anglo-American Spondylitis Consortium (TASC), Burton PR, Australo-Anglo-American Spondylitis C, et al. Association scan of 14,500 nonsynonymous SNPs in four diseases identifies autoimmunity variants. Nat Genet 2007;39:1329-37.

3 Davidson SI, Wu X, Liu Y, et al. Association of ERAP1, but not IL23R, with ankylosing spondylitis in a Han Chinese population. Arthritis Rheum 2009;60:3263-8.

4 Australo-Anglo-American Spondyloarthritis Consortium (TASC), Reveille JD, Sims AM, et al. Genome-wide association study of ankylosing spondylitis identifies non-MHC susceptibility loci. Nat Genet 2010;42:123-7.

5 Choi CB, Kim TH, Jun JB, et al. ARTS1 polymorphisms are associated with ankylosing spondylitis in Koreans. Ann Rheum Dis 2010;69:582-4.

6 Evans DM, Spencer CC, Pointon JJ, et al. Interaction between ERAP1 and HLA-B27 in ankylosing spondylitis implicates peptide handling in the mechanism for HLA-B27 in disease susceptibility. Nat Genet 2011;43:761-7.

7 International Genetics of Ankylosing Spondylitis Consortium (IGAS), Cortes A, Hadler J, et al. Identification of multiple risk variants for ankylosing spondylitis through highdensity genotyping of immune-related loci. Nat Genet 2013;45:730-8.

8 Karaderi T, Keidel SM, Pointon JJ, et al. Ankylosing spondylitis is associated with the anthrax toxin receptor 2 gene (ANTXR2). Ann Rheum Dis 2014;73:2054-8.

9 Ellinghaus D, Jostins L, Spain SL, et al. Analysis of five chronic inflammatory diseases identifies 27 new associations and highlights disease-specific patterns at shared loci. Nat Genet 2016;48:510-8.

10 Robinson PC, Leo PJ, Pointon JJ, et al. Exome-wide study of ankylosing spondylitis demonstrates additional shared genetic background with inflammatory bowel disease. NPJ Genom Med 2016;1:16008. 